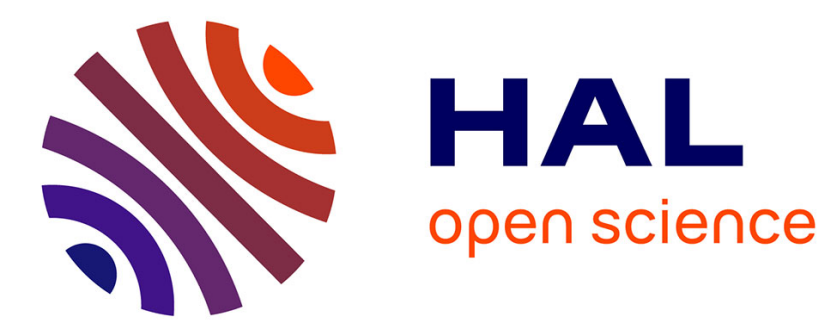

\title{
Search for superheavy elements in nature
}

\author{
C. Stephan, J. Tys, M. Sowinski, E. Cieslak, M. Meunier
}

\section{To cite this version:}

C. Stephan, J. Tys, M. Sowinski, E. Cieslak, M. Meunier. Search for superheavy elements in nature. Journal de Physique, 1975, 36 (2), pp.105-112. 10.1051/jphys:01975003602010500 . jpa-00208233

\section{HAL Id: jpa-00208233 https://hal.science/jpa-00208233}

Submitted on 1 Jan 1975

HAL is a multi-disciplinary open access archive for the deposit and dissemination of scientific research documents, whether they are published or not. The documents may come from teaching and research institutions in France or abroad, or from public or private research centers.
L'archive ouverte pluridisciplinaire HAL, est destinée au dépôt et à la diffusion de documents scientifiques de niveau recherche, publiés ou non, émanant des établissements d'enseignement et de recherche français ou étrangers, des laboratoires publics ou privés. 


\title{
LE JOURNAL DE PHYSIQUE
}

Classification

Physics Abstracts

4.490

\section{SEARCH FOR SUPERHEAVY ELEMENTS IN NATURE}

\author{
C. STEPHAN and J. TYS $(*)$
}

Division de Physique Nucléaire, Institut de Physique Nucléaire, 91406 Orsay, France

\section{SOWINSKI}

Institute for Nuclear Research, Swierk, Poland

\section{E. CIESLAK}

University of Warsaw, 00681 Warsaw, Poland

and M. MEUNIER

Laboratoire René-Bernas,

Centre de Spectrométrie Nucléaire et de Spectrométrie de masse, 91406 Orsay, France

(Reçu le 2 juillet 1974)

\begin{abstract}
Résumé. - Des essais de mise en évidence d'éléments superlourds par leur fission induite par neutrons ont été faits sur divers échantillons (minéraux, nodules de manganèse, poussière lunaire, météorite), préalablement analysés dans un séparateur de masse. Des masses subissant la fission ont effectivement été collectées dans la région de masse $A=300$. Aucune conclusion sur l'existence des éléments superlourds n'a pû être obtenue en raison d'une contamination possible de cette région de masse par des molécules contenant des atomes d'uranium ou de thorium. Cependant, la plupart des mesures de sections efficaces de fission qui ont été effectuées ne peuvent s'expliquer par la présence d'atomes d'uranium ou de thorium. Des résultats complémentaires concernant les propriétés des atomes contenus dans ces masses sont également donnés.
\end{abstract}

Abstract. - Superheavy elements have been searched for by neutron induced fission of mass separated samples. Various natural materials have been investigated : minerals, manganese nodules, lunar dust, meteoritic materials. Fissioning masses have been collected in the $A=300$ mass region. However, one cannot conclude that these masses are superheavy elements because of a possible contamination of this mass region by molecules containing natural uranium or thorium. To test for this possibility, the ratios of fast to thermal neutron events have been determined in each separated mass region. These ratios cannot be completely understood as due to the fission of $U$ or Th atoms. Some complementary results concerning the properties of the atoms contained in these masses are also given.

1. Introduction. - A few years ago, some superheavy elements were predicted by theory to have half lives of more than $10^{8}$ years, which prompted experimentalists to search for superheavy elements in nature $[1,2,3,4]$. At that time calculations had not been done about their rate of formation during the nucleosynthesis of elements. All calculations, since

(*) Present adress : Institute for Nuclear Research, Swierk, Poland. then, are pessimistic about the occurence of superheavy elements in nature and some even predict that their formation is impossible $[5,6]$. However, the parameters used in these calculations may not be known with enough precision to warrant such a drastic conclusion. For example, O. Johns [7] has shown that the possibility of formation of superheavy nuclei depends critically on the neutron density and the temperature existing in supernovae, neither of which are known with the necessary accuracy. It is inte- 
resting to note that any information about the existence of the superheavy elements could possibly shed some light on these characteristics of supernovae, if these are taken as the site of the r-process.

Most astrophysical calculations predict the r-process formation of superheavy elements to be at best a marginal process. The low abundances predicted for these elements may explain the failure of earlier experimental searches for them. Most methods of detection have exploited the natural radioactivity of such nuclei, which should decay essentially by alpha emission and spontaneous fission. This last mode of desintegration has been very much studied, either by trying to find fission fragments $[8,9,10]$ or by detecting the number of neutrons [11, 12] emitted, predicted to be about 10 for each fission [13, 14]. It seems that this method is, up to now, the most sensitive since it allows the detection of $10^{-12}$ to $10^{-15}$ gram of superheavy nuclei per gram of the sample $(\mathrm{g} / \mathrm{g})$. The sensitivity of this method depends upon the life-time of the superheavy element and the number of neutrons emitted per fission.

In this work, we have developped a method in which the only assumption about the properties of superheavy elements is that their nuclei fission when they are bombarded with fast neutrons in a reactor. As shown below, this method can reach a high degree of sensitivity and furthermore gives the mass of the superheavy element detected.

2. Experimental procedure. - The principle of the method has already been described [15]. The superheavy. elements from the sample under study are isolated with a mass separator. The separated ions so collected on a quartz plate are then bombarded with neutrons in order to drastically increase their fission probability, that is, the sensitivity of detection. The fission events are observed by the tracks they leave in the mass collector which is a quartz plate.

2.1 CHOICE OF THE SAMPLES. - Theoretically, the most stable nuclei are expected to have atomic numbers between 110 and 114. Their chemical properties should be analogous to those of nuclei which are in the same column of the Mendeleev table, that is $\mathrm{Pt}, \mathrm{Au}, \mathrm{Hg}, \mathrm{Pb}$. Concerning their physical properties, these superheavy elements are believed to be more volatile than their homologues [16]. This is why superheavy elements have been preferentially searched for in minerals which have undergone as few geological transformations as possible during which they could have been volatilized. We have chosen lead minerals such as galenas, mercury minerals such as cinabre and some minerals containing native gold or platinum. Some samples were also chosen because there were indications of the presence of superheavy elements in them. Among these were a lead glass and manganese nodules from Prof. G. N. Flerov and his collaborators who found in these samples an excess of spontaneous fissions which could not be explained by the amount of thorium and uranium they contain [9, 17]. The Manganese nodules collected on the floor of the Pacific Ocean are particularly interesting because these concretions accumulate heavy elements and consequently, possibly also, superheavy elements. They could also contain superheavy elements with a lifetime shorter than the age of the earth coming from cosmic bombardment. We have also investigated a lead mineral (cerusite) in which Irène Joliot-Curie was looking for alpha rays of unknown origin [18]. Finally, we have studied the meteorite ORGUEIL which is known to to be rich in heavy elements and some lunar powder from flight APOLLO 11 which, because of cosmic bombardments, could eventually contain superheavy elements.

It is of importance to know the quantity of uranium and thorium contained in these samples. The concentrations measured by us or other authors are indicated in table $\mathrm{I}$.

2.2 MASS SEPARATION. - These experiments were started with the two stage isotope separator of the Institut de Physique Nucléaire. However it soon became obvious that the isotope separator SIDONIE from the Laboratoire René-Bernas at Orsay [19] was particularly suitable, because of its good resolution, very low tail current and high yield (5-15\%) on the collector.

In our experiments the quantity of matter deposited in the ion source varied between 50 and $600 \mathrm{mg}$. The sample was evaporated by increasing progressively the temperature of the crucible up to $1500^{\circ} \mathrm{C}$. The extracted current was maintained between 1 and 1,5 $\mathrm{mA}$ until all the matter had disappeared, except in the case of the platinum ore for which the metal remained in the crucible. The duration of the mass separation was no more than 12 hours. During all that time the stability of the magnetic field was controlled by a nuclear resonance probe and the high voltage by a digital voltmeter connected between high precision resistors. These measurements should allow one to keep collected masses in the same position with a precision of 1/20 mass unit. Unfortunately, it seems that the ion source was not mechanically steady enough during the heating to allow such a precision in the mass determination. Furthermore, the focusing conditions might also vary during the separation process since the products which are evaporated change according to the temperature of the mineral.

The collector consisted of five quartz plates each of $80 \mathrm{~mm}$ length, $20 \mathrm{~mm}$ width and $1 \mathrm{~mm}$ thickness. These quartz plates placed in the focal plane allowed us to collect all masses between 280 to 315 . The mass calibration of the spectrometer was accomplished with Samarium chloride in the ion source. The Samarium ions, which had been pre-accelerated in the $\mathrm{Sm}^{++}$charge state but had lost one charge before entering the magnetic field, would appear at the place in the focal plane corresponding to twice the Sama- 
TABLE I

Quantity of uranium and thorium contained in the samples

Sample
Manganese nodules

Cerusite

Alaska platinum ore

50

0.06

Meteorite ORGUEIL

0.008

Lunar powder from

APOLLO II flight sample number 10084
Concentration in ppm

\begin{tabular}{cc}
$\mathrm{U}$ & $\mathrm{Th}$ \\
\hline .2 & $\overline{50}$
\end{tabular}

Methods of analysis
Chemistry

Alpha activity

Neutron induced fission

Neutron activation

$\begin{array}{ll}0.6 & 2.3 \\ 0.5 & 2.3\end{array}$

Mass spectrometry
Neutron activation

\author{
References \\ Riley and Sinhaseni, J. of \\ Marine Research 17 \\ (1958) 466.
}

This work

F. Geisler, private communication.

G. W. Reed, K. Kigoshi, A. Turkevich, Geochim. and cosmochim. acta $\mathbf{2 0}$ (1960) 122.

P. R. Field et al. p. 499.

G. H. Morisson et al., $\mathrm{p}$, 505, APOLLO II, lunar Science Conference, Science 167 (1970). rium mass. With a natural Samarium compound we were able to calibrate a mass range of 288 to 308 as shown in figure 1. Typical distances between two adjacent masses were about $12 \mathrm{~mm}$. The sizes of the spots corresponding to each mass were $10 \mathrm{~mm}$ in height and $2 \mathrm{~mm}$ in width, and so adjacent masses were very well separated from each other.

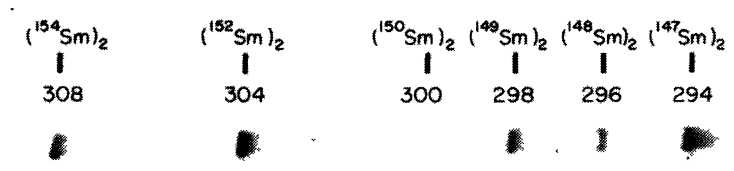

FIG. 1. - Mass calibration obtained on a photographic emulsion with samarium isotopes. One can see that the small dimensions of the spots should allow a good mass determination.

\subsection{THE CRYSTALliNE QUARTZ TRACK DETECTOR.} - Uranium and thorium are always present in natural matter and therefore produce a background which masks the true fission events. For this reason very pure monocrystals of synthetic quartz were chosen as collectors and as track detectors. The quantity of uranium and thorium they contain can be evaluated to be no more than of $10^{-12} \mathrm{~g} / \mathrm{g}$. The fission tracks measure about $8 \mu$ in this material when developed with $\mathrm{NaOH}$ [20]. Quartz has one another advantage; it is able to stand severe irradiations by neutrons, of the order of $10^{20}$ neutrons $/ \mathrm{cm}^{2}$, without losing the above properties as a detector. The quartz plates which were used in our experiments were prepared in Poland at the Institute of Nuclear Research of Swierk.
Before separation and irradiation, the quartz plates were carefully cleaned first by etching in hydrofluoric acid, then by successively rinsing in water, alcohol and diethyl ether. All this care was necessary in order to minimize the surface contamination by natural uranium and thorium. Before irradiation each of the collecting plates was covered by another quartz plate of $0.5 \mathrm{~mm}$ thickness. Since both quartz plates were developed, this system allowed one to reconstruct a complete fission event in $4 \pi$-geometry [20].

2.4 NeUTRON IRRADIATION. - The sandwiches formed by detector and collector quartz plates were sealed under vacuum in a quartz capsule before irradiation in the swimming pool reactor TRITON of the C.E.A. at Fontenay-aux-Roses. These irradiations were conducted behind a lead wall in order to reduce the gamma ray flux. The temperature of the quartz plates was measured once with a thermocouple placed between the plates during the irradiation, and found to be $140^{\circ} \mathrm{C}$. Various independent calibrations on the quality of the latent tracks as a function of temperature in quartz, had shown that under these conditions there is neither a loss in efficiency, nor a variation of the track lengths [20]. The irradiations lasted either 4 hours which corresponds to an integrated flux of $4 \times 10^{17} \mathrm{n} / \mathrm{cm}^{2}$, or a week, in which case the capsule was rolled in a cadmium foil in order to absorb out the slow neutrons. The integrated flux of the remaining neutrons of energy greater than $0.1 \mathrm{eV}$ was $2.7 \times 10^{18} \mathrm{n} / \mathrm{cm}^{2}$.

2.5 SCANNING OF THE QUARTZ PLATES. - Quartz plates are almost immediately available after irradiation since they do not become radioactive by neutron exposure. Latent fission tracks were developed with 
$\mathrm{NaOH}$ and observed with an ordinary microscope. A systematic scanning of the plates was made by counting the number of the tracks on the whole surface. This gave the track density as a function of the position on the plate. Since the masses collected from the spectrometer are localized in a well defined spot $(10 \mathrm{~mm} \times 2 \mathrm{~mm})$, from the increased density of the tracks one can be sure that these events are indeed from the collected masses. Note that because of the uniform distribution of the contamination, the tracks produced by contamination would also be uniformly distributed.

When necessary, it was possible to measure the track lengths to evaluate the kinetic energy of the fission fragments. Also, by combining the tracks in the sandwich of quartz plates, one was able to reconstruct the complete fission event, i.e. a spatial coincidence of fission tracks could be established. This way, it was possible to measure the ratio of the tripartitions (three heavy fragments) to the number of binary fissions.

3. Experimental results. - 3.1 NUMBER OF OBSERVED TRACKS. - The ultimate sensitivity of this method is limited by the number of fission tracks coming from the surface contamination by natural thorium and uranium. Under the conditions of cleaniness described above, the number of these background tracks did not exceed 30 per $\mathrm{cm}^{2}$. This number represents a reduction in background of 3 orders of magnitude since our first measurements, thus enhancing our ability to detect smaller concentrations of superheavy elements. Fissioning masses were not found in galena, lead glass and gold and mercury ores in the original experimental conditions. However, if the amount of fissionnable elements in these samples had been as much as we now find in the manganese nodules, platinum ore and cerusite, we would have detected them. This implies that in spite of the higher background of the earlier experiments, the concentration of fissionable elements in the former set of samples is not as large as in the later samples. In the platinum ore, actually, some masses gave a number of tracks $10^{5}$ times higher than the uranium and thorium background. The corresponding number was between $10^{4}$ and $10^{3}$ for the manganese nodules. But in the case of the meteorite ORGUEIL and the APOLLO 11 lunar dust, only a few fission tracks are observed above the background and these correspond to the mass numbers 280, 283 and 286 .

All the results concerning these samples are presented in table II and are also plotted in figure 2. Notice that the most intense tracks observed fall in two groups of masses, one from mass 283 to 288 and the other from mass 299 to 310 . It is possible to assert that the observed masses really come from the samples under analysis for the following reasons. If the spectrometer could have introduced contaminations of its own, we would have observed tracks in the same

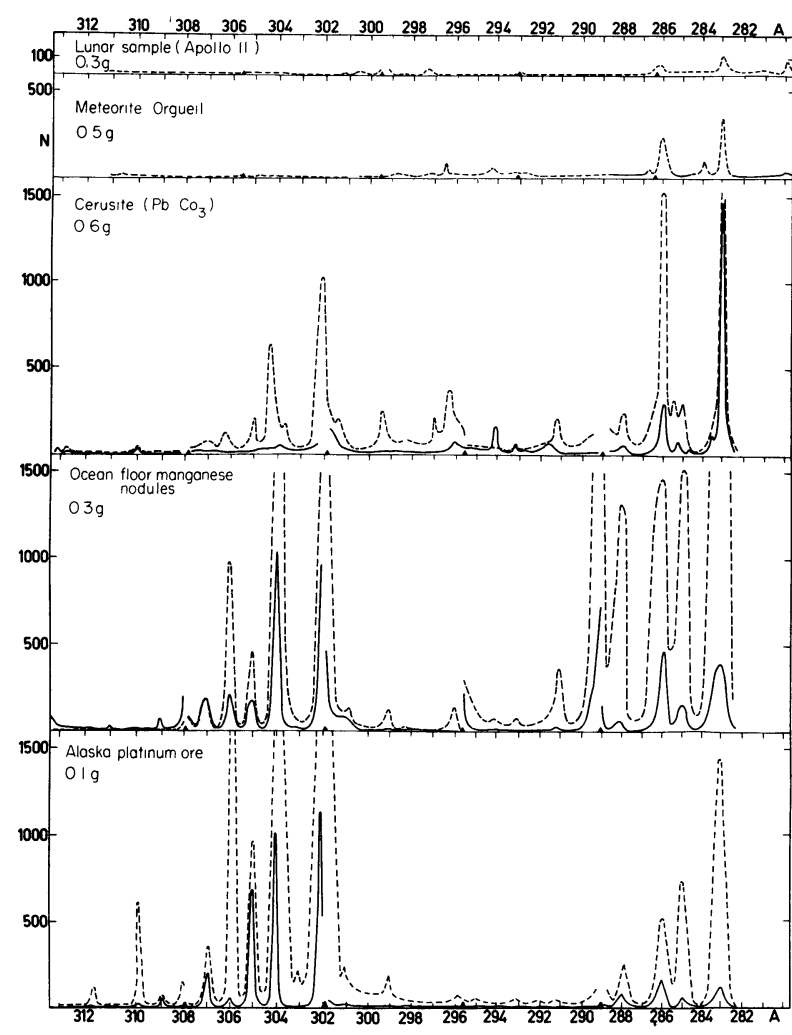

FIG. 2. - Number of fission tracks observed in quartz plates placed in the focal plane of the isotope separator SIDONIE, as a function of the position on the plate. This position is calibrated in mass numbers. For the samples shown, the dotted curves give the number of tracks obtained after a week's irradiation behind a cadmium shielding, the solid curves after 4 hours irradiation without shielding. The triangles indicate the edges of the 5 quartz plates.

locations for every sample. However there were runs made with samples such as the lunar dust which produced very few localized tracks after irradiation. These runs were made under similar conditions as, and before and after, the runs with samples which produced a high density of localized tracks. Furthermore, comparable results were obtained for mass separations of the same sample made at different times, with only a few changes in the yields of collection.

3.2 COMPARISON OF THE NUMBER OF TRACKS AFTER IRRADIATION BY SLOW AND EPICADMIUM NEUTRONS. - An identification among the collected masses can be attempted if one knows their behaviour towards fast neutron induced fissions, as compared to those induced by the whole neutron energy spectrum. To this end, two neutron irradiations can be made, one with the total reaction flux, and one with the quartz plates wrapped in a cadmium foil which excludes the thermalized neutrons. The neutrons which are not absorbed by the cadmium foil are called epicadmic neutrons.

Besides hypothetical superheavy elements, ${ }^{235} \mathrm{U}$, ${ }^{238} \mathrm{U},{ }^{232} \mathrm{Th}$ are the only known isotopes in nature in which fission occurs with reactor neutrons. The 


\section{TABLE II}

Number of fission tracks for every mass after separation of the 5 samples studied in this work. $N \mathrm{Cd}$ represents the number of fissions obtained after a week's irradiation behind a $\mathrm{Cd}$ shielding, $N$ total the number of fissions obtained after irradiation without shielding. $R$ is the ratio between these 2 numbers. As the neutron flux varies from one irradiation to another, the numbers between parentheses indicated for the nodule and platinum ore are a normalization of the ratio $R$, allowing a direct comparison with the cerusite sample.

In the last two columns, some possible molecules containing $\mathrm{U}$ and $\mathrm{Th}$ atoms are listed.

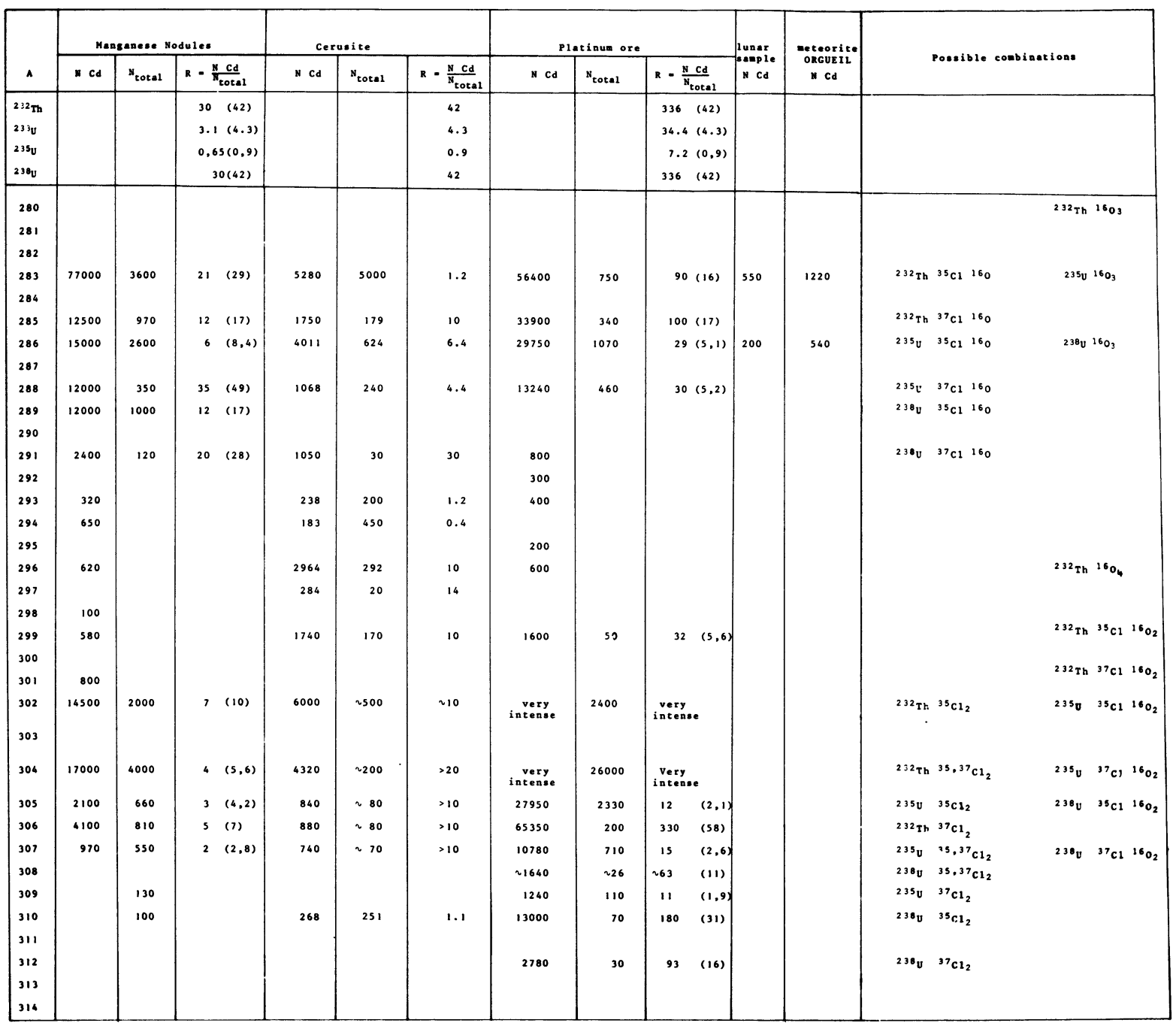

presence of transuranic elements can probably be ruled out as shown at the end of section 4 . The fission cross sections are well known for the three isotopes quoted; the thermalized neutrons induce fission in ${ }^{235} \mathrm{U}$ atoms only. Furthermore, the natural isotopic ratio ${ }^{235} \mathrm{U} /{ }^{238} \mathrm{U}$ is known to be equal to $7 \times 10^{-3}$. The presence of $U$ atoms must then match the following results : in an irradiation by epicadmic neutrons, the numbers of fissions counted at masses separated by three mass units are in the same ratio than the isotopic ratio $7 \times 10^{-3}$. For the lighter mass (corresponding to ${ }^{235} \mathrm{U}$ ) the number of fissions obtained with and without a cadmium shielding must be in the ratio of the known fission cross sections.
Such irradiations with and without a cadmium shielding have been performed. Separate detector plates were used for the two types of irradiations, and only these detector plates were etched. The results are given in table II and figure 2. For comparison, results obtained under identical conditions with a quartz plate on which ${ }^{232} \mathrm{Th},{ }^{233} \mathrm{U},{ }^{235} \mathrm{U},{ }^{238} \mathrm{U}$ had been deposited with the isotope separator are given at the top of table II. It is interesting to quote that the results obtained for these isotopes agree with those expected from the known fission cross sections, as averaged over the neutron spectrum used here.

Table II shows that among the collected masses, only those labelled as 283, 294 and 310 from the 
cerusite sample have a behaviour comparable to that of ${ }^{235} \mathrm{U}$. The other collected masses appear to behave like ${ }^{238} \mathrm{U}$ or other non-thermal fissioning nuclei, mixed with very small amounts of ${ }^{235} \mathrm{U}$.

4. Possible explanations for the results. - The observation of fissioning masses around mass number 300 constitute an indication for the existence of superheavy elements. However, one explanation for the results may lie in the fact that the masses collected and labelled as « 300 » be chemical molecules of uranium and thorium contamination. Actually, compounds like those shown in table II could appear at the locations indicated. Though the yields for the formation of molecules such as $\mathrm{UO}_{3}, \mathrm{UCl}_{2}, \mathrm{ThClO}$, are not known, since the concentration of $U$ and $T h$ in the samples lies around $10^{-6} \mathrm{~g} / \mathrm{g}$, one needs small molecule formation probability $\left(\sim 10^{-6}\right)$ to produce molecular impurities in the range of $10^{-12} \mathrm{~g} / \mathrm{g}$. Actually, we have observed the formation of ions $\mathrm{Pb}^{+}$, $\mathrm{PbS}^{+}, \mathrm{PbS}_{2}^{+}$, in the relative probabilities of $1,10^{-2}$, $10^{-5}$ during mass separations of galena which makes the above explanation reasonably plausible. Further, as shown in figure 3 , since we see abundance of masses in the range of 230 to 345 with cerusite ore, specially for the masses from 235 to 270 , it is very likely that some of the fissioning masses are due to molecular formation of molecules such as $\mathrm{UO}_{3}, \mathrm{UCl}_{2}, \mathrm{ThClO}$, the larger peaks which appear at masses 235, 251, 267,283 , suggest the presence of series of compounds, probably ${ }^{235} \mathrm{U},{ }^{235} \mathrm{UO},{ }^{235} \mathrm{UO}_{2},{ }^{235} \mathrm{UO}_{3}$. The fact that peak heights are not consistent with known isotopic abundances could be that these peaks are composed of more than one molecular combination. For example, table II, the mass 286 could arise from elements 286 and/or molecular combinations like ${ }^{235} \mathrm{U}{ }^{35} \mathrm{Cl}{ }^{16} \mathrm{O}$ and ${ }^{238} \mathrm{U}^{16} \mathrm{O}_{3}$ and so on.

The data contained in table II and the total irradiation times and fluxes allow us to estimate the absolute numbers of ${ }^{235} \mathrm{U}$ atoms. Unfortunately these data do not allow ${ }^{238} \mathrm{U}$ to be distinguished from

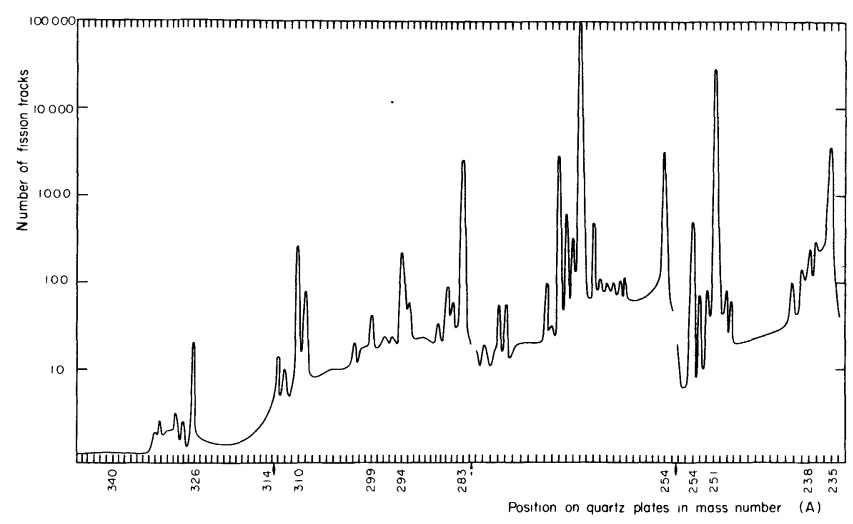

FIG. 3. - Number of fission tracks observed in quartz plates after irradiation in a reactor, as a function of the separated masses. The sample under analysis was the cerusite material. Triangles indicate the mass limits of the 4 different separations necessary to cover the whole range of masses.
${ }^{232} \mathrm{Th}$, so they must be considered together. The chemistry of molecule formation should be insensitive to isotopic differences, and the ${ }^{235} \mathrm{U} /{ }^{238} \mathrm{U}$ ratio in the samples should be approximately the natural one, $7 \times 10^{-3}$. Therefore if

$$
\mathrm{n}_{235}(\mathrm{~A}) /\left[\mathrm{n}_{238}(\mathrm{~A}+3)+\mathrm{n}_{232}(\mathrm{~A}+3)\right]
$$

is very much larger than $7 \times 10^{-3}$, the hypothesis of molecular contamination becomes very suspect, and thermal-fissioning nuclei at $\mathbf{A}$ are probably not due to molecules of ${ }^{235} \mathrm{U}$.

For some sets of masses, a ratio higher than $10^{-7}$ has effectively been observed. This is true for example for masses 305 and 308 observed in the three samples, masses 308 and 311 observed in the platinum ore. These unexplained ratios might constitute interesting indices. It would also mean that if superheavy elements are indeed being collected, they have a neutron induced fission threshold in the $\mathrm{eV}$ range. This is of particular interest, because recent calculations by Howard and Nix [26] predict that superheavy element ${ }^{249} 110$ may have a neutron fission threshold of less than $1 \mathrm{MeV}$, which is of the order of the error in the calculations.

One could also attempt to explain the results in table II assuming the formation of molecules containing trans-uranium actinide atoms, since slow neutrons induce fission in these elements with a cross section of thousands of barns. We note that at mass 294 in cerusite the ratio $R=0.4$ and at mass 309 and 310 in the manganese nodules is less than 0.2 (threshold). But if transuranium thermal-neutron fissioning atoms are present, one should observe in an ionisation chamber an alpha activity of the quartz plates of a few counts a day which has not been detected.

Even if superheavy elements really exist in the analysed samples, one could hardly believe that they are present in every fissioning mass which was found. The most reasonable assumption would be to suppose that some of these masses were due to superheavy elements of more than $10^{8}$ years life time, perhaps some others to their daughters, and the other masses to molecules containing $\mathrm{U}$ and $\mathrm{Th}$ atoms.

5. Complementary measurements. - As it appears that no conclusions can be drawn from the preceding results, further experiments have been undertaken.

5.1 The calculated masses of superheavy elements given in mass tables [22, 23, 24] correspond to a mass excess of the order of $150 \mathrm{MeV}$ to $200 \mathrm{MeV}$. This value would mean a difference of about $4 \mathrm{~mm}$ between the position of the superheavy element on the collector and the one of samarium for the same mass unit. The difference is of $2 \mathrm{~mm}$ only for $\mathrm{U}$ and $\mathrm{Th}$ molecules. However such measurements appeared to be difficult, due to the many hours needed to collect fissioning masses. The mass calibrations were made with $\mathrm{Sm}$ ions before and after the collections and 
variations were always observed between the two measurements. Considering the chemical properties of samarium, we thought that it might be interesting to search for superheavy elements in Sm Chloride itself. This way, one would obtain a precise mass calibration made at the time of separation on the collector itself. Fissioning masses were found in this Sm sample with a mass excess of at least $200 \mathrm{MeV}$, as expected for superheavy elements. We could not find a sufficient difference of behaviour between fissioning masses and $\mathrm{Sm}^{+}$ions to question the mass calibration. This result encourages us to develop a technique allowing precise measurements of collected masses.

5.2 Recent calculations of the kinetic energy of fission fragments emitted during the fission of superheavy elements predict that this kinetic energy is comparable to the one obtained in the fission of californium [14]. The fission tracks observed in quartz should then be longer if they were due to fission fragments of superheavy elements, than if due to $U$ or Th fission fragments. As it is difficult to measure the depth of a fission track with an accuracy better than $1 \mu$, measurements were made of the projected length only, for which the accuracy is of about $0.3 \mu[20]$. Until now only one fissioning mass obtained in the samarium separation has been studied that way. Another quartz plate irradiated by uranium fission fragments was developed and scanned in exactly the same conditions. The length distribution appeared to be $1 \mu$ longer in the case of the fissioning mass than for the uranium tracks. Further measurements will be made to confirm this preliminary result.

5.3 Theoretical predictions also indicate that fission into three heavy fragments might be favoured in the case of superheavy elements [13]. Three pronged events were observed in some sandwiches. However, the high density of tracks in the region of interest give random events indistinguishable from true events. Better experimental conditions will be used in the future.

5.4 From the neutron flux and the number of fission tracks observed, one can deduce the number of uranium or thorium atoms which would have been collected. One finds that the disintegration of these atoms by spontaneous fission would give very few tracks in a year. On the contrary, superheavy elements might decay by spontaneous fission more rapidly than $\mathrm{U}$ or $\mathrm{Th}$ and perhaps produce more fission tracks. Sandwiches formed by neutron irradiated quartz collectors and clean new quartz detectors, have been left in contact during eight months. The scanning of the detector plate showed very few unlocalized fission tracks.

5.5 Complex molecules like those considered here are certainly decomposed in the ion source of a mass spectrometer. An experiment is planned in which the collected masses will be reanalysed in mass by another mass spectrometer.

5.6 It should be possible to obtain the atomic number of the collected masses from their X-ray emission induced by energetic heavy ions [25]. An experiment is in preparation in which the collected masses will be bombarded by argon or krypton ions of about $6 \mathrm{MeV} /$ nucleon. The L X-rays of superheavy elements should be produced with a cross section high enough to make the experiment feasible. We will attempt to detect these $\mathrm{L}$ X-rays of about $25 \mathrm{keV}$ energy with a silicon detector of $200 \mathrm{eV}$ energy resolution. However, it must be said that this experiment is again at the limit of the method, due to the low number of collected atoms (between $10^{8}$ and $10^{10}$ ).

6. Conclusion. - Collected masses undergoing fission with reactor neutrons have been observed in the 300 mass region. This result, obtained in a few samples only, would correspond to $10^{-11}$ or $10^{-13} \mathrm{~g} / \mathrm{g}$ of superheavy nuclei in these materials. But we are unable to prove that they really are superheavy elements, because of the existence in this region of molecules formed with $\mathrm{U}$ or $\mathrm{Th}$ atoms. Complementary measurements concerning track length, mass excess and ternary fission have until now not reached enough precision to show evidence for the existence of superheavy elements. However, the comparison of the number of fission tracks obtained with reactor neutrons and epicadmic neutrons, constitute a striking result since some data could not be interpreted by the fission of $U$ or Th atoms. We hope that improvements of the techniques already developed and also the other experiments we are preparing, chiefly atomic number measurements, will allow us to give better conclusions.

Acknowledgments. - The authors are very much indebted to the late René-Bernas, director of the Centre de Spectroscopie Nucléaire et de Spectrométrie de Masse of CNRS at Orsay, who had shown so much interest for this work from its very beginning, and for the use for the isotope separator SIDONIE from his laboratory. They would also like to thank Prof. M. Riou who has been so enthusiastic for all the steps of these searches.

This work has been possible only thanks to the help we have found in a number of laboratories. The samples were given to us by many different persons, we would like to acknowledge : Dr. Pinet, Dr. Pellas and Prof. Kraut from Museum d'Histoire Naturelle in Paris for different minerals and a piece of the meteorite ORGUEIL, Prof. Allegre from University Paris VII for a piece of very ancient galena, Dr. H. Langevin-Joliot for different samples which belonged to Irène Joliot-Curie, Prof. G. N. Flerov from the Joint Institute for Nuclear Research in Dubna, for a lead glass and manganese nodules, Prof. R. Walker and Dr. F. Geisler from Washington University in St-Louis 
for the platinum ores, and Dr. M. Maurette from the CSNSM in Orsay who made the arrangements to obtain the sample of lunar dust from the flight APOLLO 11.

We are indebted to all those who have made the mass separations for us, in particular to M. Camplan for all the benefits we gained from his expertise at the head of the isotope separators. A special attention is also due to MM. Moroy, Alexandre, Obert and Wojtasiewicz. We would also like to thank Dr. Chaumont for all his good suggestions concerning these separations.

Neutron irradiations have been possible only thanks to Drs. Joly and Signarbieux from C.E.A. Saclay who have let us use important fluxes of neutrons, to Mr. Gilbert who was in charge of the preparation of the irradiations, and to the efficiency of the crew of the reactor TRITON from C.E.A. at Fontenayaux-Roses. We also thank Dr. Mory from Fontenayaux-Roses who has so kindly put at our disposal his laboratory to handle the samples after their irradiation in the reactor and Mrs Mrs.Wilczynska and Mr. Czysewski from Swierk for the scanning of the plates of quartz.

Finally, we would like to thank Oliver Johns from Berkeley for stimulating discussions and for correcting the manuscript.

\section{References}

[1] Nilsson, S. G., Thompson, S. G. and Tsang, C. F., Phys. Lett. 28B (1969) 458.

[2] Nilsson, S. G., Tsang, C. F., Sobiczewski, A., Szymanski, Z., Wycech, S., Gustafson, C., Lamm, J. L., Möller, P. and Nilsson, B., Nucl. Phys. A 131 (1969) 1.

[3] Bolsterli, M., Fiset, E. O., Nix, J. R. and Norton, J. L., Phys. Rev. Lett. 27 (1971) 681.

[4] Meldner, H. and Herrman, G., Z. Naturforsch. 24A (1969) 1429.

[5] SChramm, D. N. and Fiset, E. O., Cal. Tech. report OAP-298, August 1972.

[6] Boleu, R., Nilsson, S. G. and Sheline, R. K., Phys. Lett. 40B (1972) 517;

and Boleu, R., Nucl. Phys. A 201 (1973) 401

[7] JoHns, O., Lab. René-Bernas report LRB 74/3, Orsay, juillet 1974.

[8] Wesolowski, J. J., Jewell, W. J. R. and Guy, F., Phys. Lett. 28B (1969) 544.

[9] Flerov, G. N. and Perelygin, V. P., Atomn. Energiya 26 (1969) 520 [transl : Sov. J. At. Energy 26 (1969) 603].

[10] Price, P. B., Fleicher, R. L. and Woods, R. T., Phys. Rev. C 1 (1970) 1819.

[11] Ter-akop'yan, G. M., Ivanov, M. P., Popeko, A. G., SubboTIN, V. G., Fefilov, B. V. and Vorob'ev, E. D., Dubna Report $\mathrm{n}^{\circ}$ JINR P13-5391 (1970).

[12] Cheifetz, E., JARED, R. C., Giusti, E. R. and Thompson, S. G., Phys. Rev. C 6 (1972) 1348.

[13] Nix, J. R., Phys. Lett. 30B (1969) 1.
[14] Schmitt, H. W. and Mosel, U., Nucl. Phys. A 186 (1972) 1.

[15] Sowinski, M., Stephan, C., Czyzewski, T. and Tys, J., Intern. Conf. on Heavy ions Physics, Dubna, febr. 1971, p. 79.

[16] Nix, J. R., Proc. Int. Conf. Prop. Nucl. far from Region beta stability, Leysin, sept. 1970. CERN report 70-30, p. 1151;

and Keller, O. L., Jr, Burnett, J. L., Carlson, T. A. and Nestor, C. W., Jr., J. Phys. Chem. 74 (1970) 1127.

[17] Otgonsuren, O., Perelygin, V. P. and Flerov, G. N., Dubna report D6-4649 (1970).

[18] Curie, I., J. Phys. \& Radium 7 (1946) 313.

[19] Camplan, J., Meunier, R. and Sarrouy, J. L., Nucl. Instr. and Meth. 84 (1970) 37 and 45.

[20] Sowinski, M., Stephan, C., Czyzewski, T. and Tys, J., Nucl. Instr. and Meth. 105 (1972) 317.

[21] Muzychka, YU. A., Pashkevich, V. V. and StrutinskiI, V. M., Yadern. Fiz. 8 (1969) 716 [Transl : Sov. J. Nucl. Phys. 8 (1969) 417].

[22] Myers, W. and Swiatecki, W. J., Nucl. Phys. 81 (1966) 1. and Lawrence Radiation lab. report $\mathrm{n}^{\circ}$ UCRL 11980-1965.

[23] Viola, V. E., Jr. and Swant, J. A., Univ. of Maryland, report MNC-3783-0008 (June 1971).

[24] Fisets, E. O. and Nix, J. R., Nucl. Phys. A 193 (1972) 647.

[25] Lu, C. C., Carlson, T. A., Malik, F. B., Tucker, 'T. C. and Nestor, C. W., Jr., Atomic Data 3 (1971) 1.

[26] Howard, W. M. and NIX, J. R., Nature 247, $\mathrm{n}^{\circ} 5435$ (1974) 17-20. 